\title{
AVALIAÇÃO DA APLICAÇÃO DE PRODUTOS NATURAIS COMO CONSERVANTES EM PRODUTOS COSMÉTICOS Rosilene Machado ${ }^{1,2^{*}}$, Paulo Roberto H. Moreno ${ }^{2}$ 1 - Chemyunion Ltda., Sorocaba (SP) \\ 2 - Instituto de Química, Universidade de São Paulo (USP), São Paulo, SP rosilene.mac56@gmail.com
}

\begin{abstract}
Resumo: A busca por cosméticos eficazes e seguros tem sido constante e continua crescendo. Com este enfoque, a substituição de conservantes sintéticos pelos de origem natural vem de encontro a essa diretriz. Atendendo às expectativas do mercado de produtos cosméticos que busca formulações com menor potencial de toxicidade, e diminuindo a incidência de irritação e alergia, propõe-se o estudo do potencial antimicrobiano de alguns produtos naturais. Esses produtos já são empregados como ingredientes de produtos cosméticos no mercado nacional: Castanha-do-Pará (extrato), Breu Branco (óleo-resina), Erva Doce (óleo essencial), Cumaru (absoluto), Cupuaçu (extrato) e Pataqueira (óleo essencial). Esses produtos foram desafiados frente à microrganismos Escherichia coli (ATCC 8739), Staphylococcus aureus (ATCC 6538), Pseudomonas aeruginosa (ATCC 9027), Aspergillus brasiliensis (ATCC 16404) e Candida albicans (ATCC 10231). Os ingredientes cumarú e pataqueira apresentaram a maior inibição para a maioria dos microrganismos teste. Esses dois produtos foram considerados com potencial para desenvolvimento de conservantes naturais após maiores estudos de sinergismo com outros conservantes sintéticos de amplo espectro antimicrobiano.
\end{abstract}

Palavras-chave: conservante natural, agente antimicrobiano, extratos vegetais, produtos naturais, produtos cosméticos

\section{Application study of natural products as preservatives in cosmetic products}

\begin{abstract}
The search for effective and safe cosmetics has been constant and continues to grow. With this focus, the substitution of synthetic preservatives for those of natural origin is in line with this guideline. Meeting the expectations of the cosmetic products market that seeks formulations with less potential for toxicity, and decreasing the incidence of irritation and allergy, it is proposed to study the antimicrobial potential of some natural products. These products are already used as ingredients of cosmetic products in the national market: Castanha-do-Pará (extract), Breu Branco (oilresin), Erva Doce (essential oil), Tonka bean (absolute), Cupuaçu (extract) and Pataqueira (essential oil). These products were challenged against the microorganisms Escherichia coli (ATCC 8739), Staphylococcus aureus (ATCC 6538), Pseudomonas aeruginosa (ATCC 9027), Aspergillus brasiliensis (ATCC 16404) and Candida albicans (ATCC 10231). The ingredients tonka bean and pataqueira showed the highest inhibition for most of the test microorganisms. These two products were considered to have potential for the development of natural preservatives after further studies on synergism with other synthetic preservatives of broad antimicrobial spectrum.
\end{abstract}

Keywords: natural preservative, antimicrobial agent, plant extracts, natural products, cosmetic products.

\section{Introdução}

No mercado cosmético mundial tem se observado um aumento na demanda do por produtos naturais, principalmente nas últimas décadas. "A preferência pelo consumo verde", ou seja, por produtos elaborados com ativos naturais, é o principal fator dessa demanda. ${ }^{1}$

Os conservantes, além de apresentarem atividade antimicrobiana efetiva, devem ser seletivamente tóxicos e eficazes contra bactérias Gram-positivas, Gram-negativas, bolores e leveduras. Entretanto, devido a características intrínsecas, a grande maioria dos conservantes de origem sintética pode apresentar reações ao usuário, tais como, irritação local, dermatite de contato, hipersensibilidade e outras. ${ }^{2}$ Devido a este problema ocasionado pelos conservantes a indústria está produzindo cosméticos livres de conservantes ou com conservantes de origem natural e em associações. Dentre 
os conservantes naturais utilizados, podemos citar os óleos essenciais como uma alternativa viável devido sua reconhecida atividade antimicrobiana. ${ }^{3}$

Com este enfoque, a substituição de conservantes sintéticos pelos de origem natural vem de encontro a essa diretriz. Atendendo às expectativas do mercado de produtos cosméticos que busca formulações com menor potencial de toxicidade, e diminuindo a incidência de irritação e alergia, propõe-se o estudo de alguns produtos naturais para a avaliação de seu potencial como conservantes. Os produtos naturais selecionados para esse estudo foram os extratos de Castanha (Bertholletia excelsa Humb. \& Bonpl.), Cumaru (Dipteryx odorata (Aubl.)Willd), Cupuaçu (Theobroma grandiflorum (Wild Ex. Spreng) Schum), os óleos essências de Erva Doce (Foeniculum vulgare Mill.) e Pataqueira (Conobea scoparioides (Cham. \& Schltdl.) Benth) e o óleo resina de Breu Branco (Protium heptaphyllum (Aubl.) Marchand). Esses ingredientes foram selecionados por já serem empregados como ingredientes de uma linha de cosméticos de uma empresa brasileira,

\section{Experimental}

Ingredientes Naturais

Os óleos essenciais e extratos utilizados foram obtidos da International Flavors \& Fragrances (IFF) (Santana do Parnaíba, São Paulo), utilizados como ingredientes naturais na indústria de cosmética. $\mathrm{O}$ os produtos utilizados no estudo encontram-se listados a seguir com o nome popular da palnta, o nome científico das espécies e o tipo de extrato fornecido:

- $\quad$ Castanha-do-Pará - Bertholletia excelsa Humb. \& Bonpl.) - Brazilnut Extract IFF

- $\quad$ Pataqueira - Conobea scoparioides (Cham. \& Schltdl.) Benth - Óleo essencial das folhas

- $\quad$ Breu Branco - Protium heptaphyllum (Aubl.) Marchand - Óleo-resina

- $\quad$ Erva Doce - Foeniculum vulgare Mill. - Óleo essencial

- Cumaru - Dipteryx odorata (Aubl.)Willd. - Tonka Bean Absolute IFF

- $\quad$ Cupuaçu - Theobroma Grandiflorum (Wild Ex. Spreng) Schum - Extrato

\section{Determinação da Atividade Antimicrobiana}

A atividade antimicrobiana foi avaliada utilizando-se o método de microdiluição em microplacas, frente aos microrganismos Escherichia coli (ATCC 8739), Staphylococcus aureus (ATCC 6538), Pseudomonas aeruginosa (ATCC 9027), Aspergillus brasiliensis (ATCC 16404) e Candida albicans (ATCC 10231) e a determinação da porcentagem de inibição de crescimento foi realizada por leitura em leitor de microplacas em $\lambda=630 \mathrm{~nm},{ }^{4,5}$ com exceção do experimento para C. albicans e A. niger, onde foi feita a leitura visual das placas. As amostras dos ingredientes naturais foram diluídas em DMSO:MeOH (1:1) e preparadas soluções adequadas para se obter as concentrações de 2,0 mg/mL, com exceção do extrato de Castanha-do Pará que, por motivos de solubilidade, foi testado.na concentração de $1,0 \mathrm{mg} / \mathrm{mL}$ Dessa maneira, as concentrações finais no meio de cultura para o ensaio foram respectivamente de 100 e $50 \mu \mathrm{g} / \mathrm{mL}$ no poço.

Como controle de sensibilidade das cepas microbianas foram empregadas soluções de $1 \mathrm{mg} / \mathrm{mL}$ dos antibióticos ciprofloxacino para bactérias, e nistatina para os fungos. Para cada controle positivo tomou-se $10 \mu \mathrm{L}$ dessa solução para que a concentração final fosse de $0,05 \mathrm{mg} / \mathrm{mL}$ em cada réplica 


\section{Resultados e Discussão}

A atividade antimicrobiana dos ingredientes naturais foi avaliada frente a cinco microrganismos distintos, duas bactérias Gram-negativas, uma Gram-positiva e dois fungos, um filamentoso e outro leveduriforme. A escolha dos microrganismos utilizados nos testes microbianos compendiais está diretamente relacionada ao fato deles serem potenciais contaminantes patogênicos que podem ser encontrados no ambiente da manufatura de produtos farmacêuticos e cosméticos. ${ }^{6} P$. aeruginosa é uma bactéria Gram-negativa não fermentadora comumente encontrados na tubulação de água e resistentes à alguns agentes bactericidas, sendo representante de contaminação em cosméticos, a presença deste microrganismo pode levar a sérias infecções oculares entre outras patogenias. ${ }^{7}$ Já a presença de E. coli, bactéria Gram-negativa fermentadora, é indicativo de contaminação fecal, o que sugere uma falta de higiene do local de fabricação e/ou dos colaboradores. ${ }^{8}$ S. aureus, Gram-positiva, é uma das bactérias patogênicas mais comuns encontradas em infecções de pele como furúnculos, impetigo, conjuntivite, foliculite. ${ }^{9}$

Quanto aos fungos, bolores e leveduras, o ensaio mandatório para a gênero dos bolores é a verificação da presença de $A$. brasiliensis, pois este habitualmente está presente no ar, podendo contaminar e germinar produtos farmacêuticos e cosméticos, promovendo descoloração e deterioração. Cosméticos podem apresentar ingredientes ricos em nutrientes provenientes de substratos orgânicos como açúcar, proteínas, lipídeos, o que favorece o crescimento de leveduras osmofílicas, como C. albicans, que podem alterar a estabilidade da formulação devido à fermentação do açúcar se estiver presente na formulação. ${ }^{6}$

Usando esses microrganismos como modelo foi feita uma triagem do potencial antimicrobiano dos ingredientes naturais selecionados. A inibição obtida para cada um dos ingredientes pode ser vista na Tabela 1. Como pode ser observado nenhum dos produtos foi capaz de inibir em $100 \%$ todos cinco microrganismos acima discriminados. Além disso, frente a A. brasiliensis apenas os extratos de cumarú e cupuaçu apresentaram atividade, e frente a $C$. albicans apenas o Breu-Branco e o óleo essencial da pataqueira foram capazes de inibir seu crescimento. Por outro lado, os extratos de Castanha-do-Pará e o óleo de Erva-doce não apresentaram nenhuma inibição. Frente aos resultados obtidos, o absoluto de cumarú e o óleo essencial da pataqueira foram os mais ativos frente aos microrganismos testados.

Para serem considerados promissores agentes antimicrobianos, extratos vegetais devem apresentar concentração inibitória mínima abaixo de $100 \mu \mathrm{g} / \mathrm{mL},{ }^{10}$ o que não ocorreu para a maioria das amostras avaliadas. Esse fato não significa que seu potencial antimicrobiano não possa ser aproveitado. Estudos têm demonstrado que o efeito sinérgico proveniente da associação entre antibióticos e produtos naturais pode promover novos tratamentos para doenças infecciosas, superar a resistência bacteriana, reduzir o uso desses fármacos e consequentemente seus efeitos colaterais. Como exemplo, pode ser citada a combinação de um extrato de sementes de uva à anfotericina $\mathrm{B}$, que foi capaz de reduzir em $75 \%$ a concentração do fármaco e manter o nível de inibição frente ao microrganismo avaliado. ${ }^{11}$ Diante do apresentado, pode-se considerar a realização de estudos adicionais avaliando a sinergia entre os extratos de cumaru e o óleo essencial da pataqueira e substâncias antimicrobianas sintéticas. 
Tabela 1- Atividade antimicrobiana dos ingredientes naturais empregados em formulações cosméticas frente $S$. aureus, E. coli, P. aeruginosa, C. albicans e A. brasiliensis (concentração do inóculo $2 \times 10^{3} \mathrm{UFC} / \mathrm{mL}$ ).

\begin{tabular}{|c|c|c|c|c|c|}
\hline \multirow[b]{2}{*}{$\begin{array}{l}\text { Amostras } \\
(2 \mathrm{mg} / \mathrm{mL})\end{array}$} & \multicolumn{5}{|c|}{ \% de inibição } \\
\hline & $\begin{array}{c}\text { E. coli } \\
\text { (ATCC 8739) }\end{array}$ & $\begin{array}{l}\text { P. aeruginosa } \\
\text { (ATCC9027) }\end{array}$ & $\begin{array}{c}\text { S. aureus } \\
\text { (ATCC 6538) }\end{array}$ & $\begin{array}{c}\text { C. albicans } \\
\text { (ATCC 10231) }\end{array}$ & $\begin{array}{r}\text { A. brasiliensis } \\
\text { (ATCC 16404) }\end{array}$ \\
\hline Cumarú & 100,00 & 100,00 & 90,00 & 0,00 & 100,00 \\
\hline Cupuaçú & 100,00 & 70,00 & 90,00 & 0 & 100,00 \\
\hline Breu Branco & 100,00 & 0,00 & 0,00 & 100,00 & 0,00 \\
\hline Erva-doce & 0,00 & 0,00 & 0,00 & 0,00 & 0,00 \\
\hline Pataqueira & 100,00 & 100,00 & 23,63 & 100,00 & 0,00 \\
\hline Castanha-do-Pará* & 0,00 & 0,00 & 0,00 & 0,00 & 0,00 \\
\hline \multicolumn{6}{|l|}{ Controles $^{* *}$} \\
\hline Ciprofloxacina & 100,00 & 99,23 & 93,19 & - & - \\
\hline Nistatina & - & - & - & 100 & 100 \\
\hline
\end{tabular}

* Extrato testado na concentração de $1 \mathrm{mg} / \mathrm{mL}$

** Concentração dos antibióticos $50 \mu \mathrm{g} / \mathrm{mL}$

\section{Conclusões}

Nenhum dos ingredientes analisados foi capaz de inibir completamente o crescimento de todos os microrganismos teste, o que indica que não poderiam ser usados isoladamente como conservantes. $\mathrm{O}$ óleo de Erva-doce e o extrato da Castanha-do-Pará não apresentaram atividade antimicrobiana frente a nenhum dos microrganismos. Os ingredientes cumarú e pataqueira foram os mais ativos nos ensaios, sendo considerados promissores para estudos de sinergismo com outros conservantes sintéticos de amplo espectro antimicrobiano.

\section{Agradecimentos}

Agradecemos à IFF (Santana do Parnaíba, São Paulo) pelo fornecimento das amostras e por possibilitar R. M. realizar seu Mestrado Profissional em nosso programa, bem como para a Chemyunion Ltda. por seu apoio no desenvolvimento da pesquisa.

\section{Referências}

1. Packer, J.F.; Luz, M.M.S. Rev. Bras. Farmacog. 2007, 17, 102.

2. Lee, E.; An, S.; Choi, D.; Moon, S.; Chang, I. Contact Derm. 2007, 56, 131.

3. Barakat, H. Br. J. Appl. Sci. Technol. 2014, 4, 1934.

4. Moreno, P. R. H.; Lima, M. E. L.; Caruzo, M. B. R.; Torres, D. S. C.; Cordeiro, I.; Young, M. C. M. J. Essent. Oil Res. 2009, 21,190.

5. Lima, M. E. L.; Cordeiro, I; Young, M. C. M.; Sobral, M. E. G.; Moreno, P. R. H. Pharmacologyonline 2006, 3, 589. 
6. Denyer, S. P.; Baird, R. M. Guide to microbiological control in pharmaceuticals and medical devices, $2^{\text {nd }}$ ed.; CRC Press: Boca Raton, USA, 2007.

7. Budecka, A.; Kunicka-Styczyńska, A. Biotechnol. Food Sci. 2014, 78, 15.

8. Okeke, I. N.; Lamikanra, A. J. Appl. Microbiol. 2001, 91, 922.

9. Tan, A. S. B.; Tüysüz, M.; Ötük, G. Pak. J. Pharm. Sci. 2013, 26, 153.

10. Moreno, P. R. H.; Costa-Issa, F. I., Rajca-Ferreira, A. K., Pereira, M. A. A.; Kaneko, T. Curr. Top. Med. Chem. 2013, 13, 3040.

11. Hemaiswarya, S.; Kruthiventi, A. K.; Doble, M. Phytomedicine 2008, 15, 639. 